Old Dominion University

ODU Digital Commons

Teaching \& Learning Faculty Publications

Teaching \& Learning

$11-2021$

\title{
Middle Level Teacher Recruitment: Challenging Deficit Narratives
}

Christina Lunsmann

University of South Carolina - Sumter

Jori S. Beck

Old Dominion University, jbeck@odu.edu

KaaVonia Hinton

Old Dominion University, khintonj@odu.edu

Bettie F. Perry

Old Dominion University, bperr001@odu.edu

Follow this and additional works at: https://digitalcommons.odu.edu/teachinglearning_fac_pubs

Part of the Curriculum and Instruction Commons, and the Junior High, Intermediate, Middle School Education and Teaching Commons

\section{Original Publication Citation}

Lunsmann, C., Beck, J., Hinton, K., \& Perry, B. (2021, 2021/10/20). Middle level teacher recruitment: Challenging deficit narratives. Middle School Journal, 1-27. https://doi.org/10.1080/

00940771.2021 .1978788

This Article is brought to you for free and open access by the Teaching \& Learning at ODU Digital Commons. It has been accepted for inclusion in Teaching \& Learning Faculty Publications by an authorized administrator of ODU Digital Commons. For more information, please contact digitalcommons@odu.edu. 


\begin{abstract}
Perceptions of middle level learners vary, and unfortunately, some are deficit-oriented, labeling young adolescents as "hormonal" and "erratic" without a deep understanding of their emotional and physical development or the knowledge and skills that they bring to a classroom. In this paper, we provide empirical evidence for this deficit narrative-including the marginalization of middle level learners - from interviews conducted with teacher candidates in elementary, middle, secondary, and K-12 programs in two different states. Three themes around perceptions of teaching middle grades students are shared: adult needs and interests, resistance to student agency, and challenging the deficit narrative. We posit that developing a broader understanding of young adolescents might inform and inspire teacher candidates to choose to become middle school teachers. Thus, we encourage an asset approach to recruitment of middle level teacher candidates entering teacher preparation programs, and we offer recommendations for middle level recruitment into teacher education programs with an explicitly asset lens.
\end{abstract}

Keywords: middle level teacher candidate recruitment; young adolescents; perceptions of teaching middle school 


\section{Introduction}

Some experts estimate that 316,000 new teachers will be needed nationally by the year 2025 (Sutcher et al., 2016). Specific areas, such as math, science, and special education, have annual shortages that are generally consistent across states. For example, in many states, middle level education is one of the top critical shortage areas (South Carolina Department of Education, 2020; Virginia Department of Education, 2020). Teacher preparation and recruitment are inextricably linked, and teacher education programs must be poised to help address the teacher shortage by recruiting and selecting teacher candidates (TCs), particularly for middle schools, who have (or have the potential to develop) asset-oriented beliefs about young adolescents. We must be mindful of how we select and recruit teacher candidates with certain dispositions and attributes, and we must pay attention to how we prepare TCs to work with middle level students.

Despite the middle school years' critical role in student long-term success (Balfanz, 2009) and the need for specialized middle grades preparation (Bishop \& Nagle, 2016), fewer than $25 \%$ of middle level educators are prepared in specialized programs to teach young adolescents (Faulkner et al., 2017; Howell et al., 2018). The Association for Middle Level Education (AMLE; formerly National Middle School Association [NMSA], 2010) described essential attributes of middle level educators - challenging, developmentally responsive, empowering, and equitable — that specialized preparation could help foster. While researching our own teacher preparation programs, however, we uncovered a deficit narrative about middle school students (Author 4 et al., in press). In that questionnaire study, which inspired the current manuscript, as many as $60 \%$ of the teacher candidate responses indicated deficit views of middle school students. 
Deficit thinking ascribes failure to individuals based on perceived cognitive, social, familial, or aspirational inadequacies (Valencia, 1997). Asset-oriented thinking, instead, perceives the role of institutional elements in individual success and values funds of knowledge (Moll et al., 1992). Moreover, an asset orientation is aligned with AMLE's This We Believe (Bishop \& Harrison, 2021) characteristics including: "Educators value young adolescents and are prepared to teach them"; "curriculum is challenging, exploratory, integrative, and relevant"; and "students and teachers are engaged in active, purposeful learning" (p. 14).

In this paper, we aim to extend the notion of deficit and asset approaches to middle level learners based on our own research (Author 4 et al., in press). We provide additional empirical evidence - gleaned from interviews with TCs in elementary, middle level, and secondary programs - for a pervasive deficit narrative. The responses to the questionnaire in the original study and current interviews often dismissed middle level learners as "hormonal" and "erratic" without a deep understanding of their emotional and physical development or the knowledge and skills that they bring to a classroom. As Lesko and Mitschele (2013) pointed out,

The images of teenagers, wild and irreverent, are ubiquitous and durable...This 'nature' of early adolescence seems to go unquestioned, and that inexorable nature becomes the foundation upon which middle grades schools are administered, and classrooms are managed and lessons taught. (p. 107)

Like the authors, we question the view of middle level learners as emotional and unreliable, and we posit that they are likely to act in stable and trustworthy ways when given the opportunity.

The pervasive deficit narrative among TCs found in our initial study presents additional considerations for middle level TC recruitment. The presented data have implications for recruitment and are shared as a means of moving from research to practice. For the purposes of 
this paper, we refer to internal recruitment mechanisms for encouraging current college students to teach middle school specifically. Programs such as teacher residencies (e.g., National Center for Teacher Residencies, 2021) and alternative routes to licensure recruit candidates from outside of the profession. However, we see current TC populations as fruitful areas for recruitment as well and will expand on this rationale below. While we provide examples of what this recruitment could look like in practice, we conceptualize it as carefully scaffolded experiences between future educators and middle level learners in which TCs are positioned to withhold judgment while learning from students. The deficit narratives we encountered demonstrated a marginalization of middle level learners, and to mitigate this marginalization, we explore practical suggestions to middle level teacher recruitment with an explicitly asset lens.

\section{From a Deficit to an Asset Orientation}

Deficit approaches are part of the history of education in the United States and consider "the languages, literacies, and cultural ways of being of many students and communities of color as deficiencies to be overcome" (Paris \& Alim, 2014, p. 87). As teacher educators, we are concerned about TCs' mindsets about historically marginalized PK-12 students, particularly because of systemic racism in American society (e.g., DiAngelo, 2018).

Moll and colleagues (1992) conducted germinal work with Mexican-American families regarding their funds of knowledge, or the families' skills and traditions that were not being recognized in school. The research team brought these funds of knowledge into school and the curriculum; in one instance, a family member made candy with the class and the teacher connected this to an economics lesson. Such activities incorporate students' community resources and allow for quality instruction that goes beyond teacher-centered approaches (Moll et al., 1992). In the middle level specifically, responding to student voices has been an effective 
means of supporting achievement and other social-emotional goals (Lounsbury, 2013). Thus, young adolescents benefit greatly from incorporating their funds of knowledge - their community, home, and environmental experiences — into the classroom. When middle level students are viewed as "forever becoming" (Lesko \& Mitschele, 2013, p. 125) rather than agentic individuals, students are less likely to be permitted to use their funds of knowledge to achieve in schools. We encourage an asset approach to middle level teacher recruitment and preparation; in the current manuscript, we focus on recruitment specifically. Next, we explore the marginalization of school-age children to establish the need for specialized teacher recruitment.

\section{Marginalization of Children in Schools}

Historically, groups who do not comprise the majority of citizens have been labeled "minorities." However, Harper (2012) argued that this language implies that those outside of the dominant, Anglo-European culture are less important than those within it. Social and political systems benefit the dominant group and minoritize and marginalize people outside of it.

Minoritized demonstrates that U.S. social institutions are constructed to maintain the dominant culture's disproportionate representation and non-dominant cultures" "underrepresentation and subordination" (Harper, 2012, p. 9). Marginalization, which results from minoritization, consigns people to a secondary social status and hinders full participation in society (Granger, 2013). Marginalization has primarily referred to demographics such as race, ethnicity, sexual orientation, gender, or religion. Here we explore marginalization of children because, although they comprise the majority, they are often hindered from full participation in their education (Mayall et al., 1996). We need to recruit teachers who recognize students' diverse talents and funds of knowledge and can support them holistically in their growth. We feel it is important to note that our use is in no way intended to take attention away from the link between 
marginalization and demographics. In fact, we believe demographics play a significant role in marginalizing young adolescent learners. While we posit that age is a primary cause of this marginalization, most children in U.S. schools are also students of color. Thus, many children will be marginalized for intersectional reasons, and this should be explored further.

\section{The Sociology of Childhood}

Literature on youth marginalization is largely related to health. Mayall (1998) explored children as a marginalized group in an effort to develop a sociology of child health. This work indicated that children's marginal status is often justified because their moral decision-making and reasoning are compared with adults. Because they are dependents, policies related to children often focus on their needs rather than rights. These needs are constructed by adults according to their cultural and social lenses and are designed to serve adult interests (Woodhead, 1997). Much of social life excludes children, making their interests and views invisible while disproportionately affecting them (Casas, 1997). Correcting this injustice begins with staffing schools with teachers who are advocates for diverse youth. Mayall (1998) concluded that child oppression is obvious in schools, where their movements are restricted in crowded classrooms and learning is controlled. He explained that their minority status is evident in the curriculum, as "what children may want to learn gives place to political agendas" (p. 279). Also, curriculum goals are prioritized over their health; drinking, eating, exercising, and even using the restroom require permission. Teachers determine what, how, and when students learn; thus, curriculum design and the physical design of schools serve to illustrate children's marginalized status.

James and Prout (1997) based the sociology of childhood on the idea that "children should be seen as already social actors not beings in the process of becoming such" (p. vii). This idea contrasts previous notions about child socialization and development, which expected them 
to be "natural, passive, incompetent and incomplete" (p. x). The view presented here is of children as agentic, social, and cultural actors who work with adults to determine the direction of their lives. As a marginalized group, they do not have power over their lives (Mayall et al., 1996), and schools rarely grant them agency. We acknowledge that others also recognize that children should have agency and suggest approaches to middle level curriculum that prize funds of knowledge (Salas et al., 2013), student voice (Salas et. al., 2013), and learners as teachers (Van Overschelde et al., 2017). This change begins with teacher recruitment.

\section{Student Agency}

An understanding of the importance of student agency must be prioritized during teacher recruitment. When schools do allow students to enact agency, they raise a child's status from an "invisible object of design to an active, visible presence" (Clark, 2010, p. 3). Student agency has been defined as the "desire, ability, and power to determine their own course of action" (Vaughn, 2018, p. 63). In schools, agency can be cultivated through students making choices about what and how they learn based on their preferences and abilities (Wall et al., 2018). Agency can be enacted through dispositions, motivation, and position. The agentic dispositions — or propertiesthat students can hold include intentionality, forethought, self-regulation, and self-reflection (Bandura, 2006). Holding these dispositions influences students' sense of agency and ability to act intentionally. Agency is determined by students' efficacy and forethought, and while it depends on dispositions, students' sense of agency will vary based on the situation.

Various obstacles hinder fostering student agency, including the assessment-based accountability movement and teacher knowledge of agency (Vaughn, 2018). The accountability movement pressured educators to focus on "directive instruction, offering few opportunities for students to make choices about what and how they learn" (Vaughn, 2018, p. 63). When teachers 
do attempt to foster student agency, they may be discouraged by the curriculum and their supervisors. Teachers may feel compelled to strengthen students' agency but may have experienced little professional development or preparation on the topic or on advocacy (DeMinkCarthew \& Bishop, 2017). Thus, they may have difficulty incorporating the theory into practice (Vaughn, 2018). Despite these obstacles, agency must be considered during recruitment, as it benefits all parties: those in the dominant culture and those who are historically marginalized. When adults listen to children, both children and adults are supported (Kirby et al., 2003).

\section{Teacher Preparation}

Middle level teacher preparation must include experience teaching in the middle level and working with middle level faculty in addition to a focus on: young adolescent development; middle school structure; curriculum; planning, teaching, and assessing; advocacy; and social justice (McEwin \& Smith, 2013). Social justice is most related to fostering an asset orientation in TCs. Teacher preparation programs should foster "a disposition that cultural diversity is a strength to be built upon rather than a deficit to be remediated" (McEwin \& Smith, 2013, p. 688). In other words, it should foster the belief that students' funds of knowledge are valuable. Teacher preparation should also encourage curriculum that incorporates students' interests (Vagle, 2013). As we will discuss, many TCs do not hold these beliefs about middle level learners, and we must use caution in recruiting preservice teachers to ensure these beliefs are fostered.

Positioning students as agentic runs counter to the current climate of accountability and standardization within countries such as the United States (Cook-Sather \& Youens, 2007). Yet, student agency is critical to transforming education. Thus, it is important for TCs to have scaffolded, productive experiences when working with students. Teacher preparation is a broad field that includes many components including curriculum, field experiences, and licensure 
requirements. For the purposes of the current manuscript, we chose to focus specifically on recruitment into teacher preparation programs due to the increasing focus on teacher shortages nationally (Sutcher et al., 2016). Furthermore, we focused on internal recruitment of current college students and TCs into middle level programs and careers, specifically. As colleges of education innovate to attract future teachers amid the pressures of declining enrollment and teacher shortages, it is important to keep PK-12 students at the forefront. Cook-Sather and Youens (2007) have described programs in the United States and England in which PK-12 students are positioned as mentors to TCs. Models like these should be expanded to help TCs shift their focus from themselves (Fuller, 1969) to their students. We argue that this is particularly important during recruitment so that TCs understand who they are serving.

\section{The Project and the Context}

The current project began as a study that took place in two teacher preparation programs in the southern U.S. The purpose was to better understand TCs' perceptions of middle level learners to determine why they did or did not wish to teach young adolescents, so we conducted a total of 26 interviews. All interviewed candidates could potentially teach middle level learners, as elementary certification extends to grades 5 and 6 in the respective states, and the secondary certification includes grades 6 through 12. Both programs aim to challenge deficit assumptions, and all interviewees had taken at least the educational foundations course (although most participants had taken multiple education courses).

\section{Program Descriptions}

The first studied program was at Southern College, a small, liberal arts college in a rural area in the southern United States. The education department includes three programs: elementary, middle level, and secondary. All majors are required to participate in diverse 
practicum experiences. Elementary majors receive placements in early childhood (kindergarten through grade 2) and upper-elementary (grades 3 through 5). Middle level majors are required to complete placements in upper-elementary (grades 4 or 5) and middle school (grades 6 through 9) in each of their content areas of focus (math, social studies, science, or language arts). Secondary majors must complete a field placement in middle school (grades 6 through 9) and in high school (grades 9 through 12). Much of the coursework within the programs is focused on developing an asset orientation toward all learners (McEwin \& Smith, 2013) to challenge any deficit beliefs that TCs may bring to the program ${ }^{1}$. Many of the articles included in this manuscript are also used with TCs to provoke discussion about students, families, and communities (e.g., Lesko \& Mitschele, 2013). The first course that TCs take focuses on inequities in public schooling and requires 20 hours of observation at all school levels (elementary, middle, and high school). They are taught to use a reflective process that they engage with throughout the program, and one section of the reflection asks TCs to challenge their own assumptions. They receive detailed feedback from their peers and their instructor on these reflections.

Eastern University, a large, doctoral-granting university with high research activity, was the second site for the study and includes early childhood, elementary, and secondary education programs. The master's program in elementary education is offered with a concentration in middle school education (grades 6-8). Located in an urban center, the College of Education benefits from relationships with many local school districts. All candidates begin their programs by taking an introductory course focused on the foundations of education that includes a 30-hour early field experience that could be completed at any level—including middle school. In this course, TCs are exposed to asset-based approaches, social justice, and student agency.

\footnotetext{
${ }^{1}$ While both of our teacher education programs include asset-based approaches, we note this here not to set up our programs as models, but rather to provide context for the experiences of our TCs.
} 
Elementary candidates complete a practicum in the early elementary grades (grades K-2), upper elementary grades (grades 3-5), or middle level grade 6. They complete their student teaching in a grade level where they did not complete their practicum. Similarly, secondary candidates complete a practicum at either the middle or high school level. TCs complete student teaching in the grade level that they did not complete their practicum. Thus, all TCs leave their programs with some experience in middle grades education except for early childhood candidates unless they complete their initial observations in a middle school. Faculty in each of the three programs have worked hard to keep the curriculum updated and relevant, and all programs require foundations of education, assessment, classroom management, and technology courses.

\section{Making Sense of the Data}

The interviews built on a questionnaire that was conducted at Eastern University. The results demonstrated a persistent deficit view of middle level learners, and the researchers designed the current project to uncover why this negativity toward the middle level exists. The interview participants' demographics are delineated in Table 1.

[Insert Table Here]

Interview questions focused on TCs' experiences with middle schoolers and their perceptions of teaching middle school including benefits, disadvantages, and their intentions to teach at this level. Data analysis was conducted iteratively in multiple rounds according to Saldaña's (2009) guidelines for qualitative coding. As we worked to identify themes, we discovered a concept that we had not originally captured in our research questions and design. The deficit narrative present in much of our data illustrated a need to view it in the context of teacher recruitment. Thus, while the discussion in this paper is derived from working with data, we view this as a research-topractice paper and invite interested individuals to read about our methods in the appendix. 


\section{Toward Effective Teacher Recruitment: Understanding Teacher Candidates' Perspectives and Experiences to Connect Research to Practice}

The goal in presenting these data is to provide empirical evidence of the pervasive deficit narrative that our TCs have toward middle level students in order to facilitate discussion of assetoriented recruitment. Because most TCs in our programs will be certified to work with young adolescents, we see asset-oriented programs as an opportunity to recruit elementary or secondary TCs into middle level positions. We refer to this process as recruitment, since TCs who initially pursued other grade levels could possibly be converted to the middle level, especially since elementary and secondary grade levels overlap with middle grades. For instance, elementary certification includes grade 6 and secondary includes grades $6-8$. Thus, TCs could teach middle grades despite their chosen program. It is important for us to understand if deficit assumptions were a factor in their decision not to pursue middle level education specifically so that we can challenge these assumptions. While we recognize that a deficit view of young adolescents exists in the media, we believe that the pervasive, deficit narrative that we uncovered extends beyond this cultural stigma. Teacher education programs should lead TCs in interrogating and disrupting ideas about adolescence in popular culture and society directly to help TCs see adolescence as a social construct that views young people as homogeneous and rebellious (Lesko \& Mitschele, 2013). As conveyed in the data below, TCs held strong beliefs about young adolescents' fixed dispositions and frequently cited their developmental level as a primary cause of the negative attitudes they perceived. Although our participants were already TCs, they often viewed middle school students as individuals with fixed identities rather than as developing human beings.

We posit that this deficit narrative contributes to the marginalization of middle level learners, and recruitment efforts should serve to challenge it. Our data indicate that the deficit 
narrative is present even when TCs believe they are advocating for young adolescents. While the data were collected from multiple programs within two universities, the themes were present across programs. The themes that we identified were: (a) a focus on adult needs and interests (Mayall, 1998; Woodhead, 1997), and (b) a resistance to student agency [including voice, choice, interest, meaning, effort, and control (Wall et al., 2018) and intentionality, forethought, selfregulation, and self-reflection (Bandura, 2006)]. Another, uncommon perspective present in the data challenges the deficit narrative and aligns with James and Prout's (1997) understanding that children should be seen as social actors, not in the process of becoming such. The uncommon perspective is used to make a stronger connection with recruitment opportunities.

Understanding our TCs' beliefs and perspectives on teaching middle level students has implications for our own recruitment practices. Thus, after each theme, we provide implications for practice. Based on the projected need for middle level educators, as well as the pervasive deficit narrative about middle level learners in our teacher preparation programs, we propose a multifaceted recruitment initiative that is grounded in an asset approach to middle level learners. Although national teacher shortages and declining enrollment numbers are a cause for concern for many teacher educators, we have been impressed with the innovation in recruitment in many programs. We wanted to highlight this innovation and assert the need for PK-12 student agency within recruitment as well as attention to the assets students bring.

\section{Adult Needs and Interests}

Most prominent in the data was the pervasive focus on adult needs and interests. This primarily manifested as a discussion about the difficulty of teaching middle school and how teachers can support students. Ashley, an elementary major from Southern, said that middle level learners are at "an influential age" and teachers "can really change a student's life and influence 
them in a way that's going to help navigate how their life goes and who they are as a person in the future." She continued by asking, "Do I want to put myself in that? Do I want to be a part of that or do I not?" Shelby, a secondary major from Eastern, did want to be a part of that transition. She said, “There's a lot of situations [where students] don't have the best home environment. So, creating a space that they can exist and feel comfortable and enjoy their time in school is something that I want to be able to do for kids that [sic] don't have that situation at home."

Carmen, a Southern middle grades major, illustrated that some TCs can have a positive perception of middle level learners while still focusing on their own interests. She explained that she wanted to teach middle school because they were "the forgotten children." She explained, The reason I chose middle grades was simply because I actually like them. I like where they are cognitively and their development. I like their interests, things that they talk about ... I like being around them, so I think it would be way more enjoyable for me. Becky, another middle grades major from Southern, also focused on what is best for her, "I really want to teach eighth grade because that's the transition from middle to high and I want to be there for them." Olivia, also a Southern middle grades major, said that middle school is "crazy" and that teachers were not perceived as authority figures. She said that the classes were "out of control, talking . . . ignoring the teacher." She believed that working in this environment would make her a better teacher, "I can learn a lot from it and it will help me because I plan to have kids, so it will help me be a better parent. And like, being a better person patience-wise." Molly, an Eastern secondary education major, discussed the need to develop toughness to be a middle school teacher. She recognized the effect of hormones and physical changes on students' actions and explained, "They're going to pick on you and you have to learn how to let it bounce off. . . You have to learn to laugh with them and understand that it's not you that they are 
making fun of. They are experiencing something, and you happen to be in the line of vision." Brianna, an Eastern secondary major, echoed the idea that teaching middle school will be difficult, saying, "I think it's going to be really hard because [of] the transition on those kids . . . most of their attention span might not be very long. I'm just going to have to do my best."

Many TCs also discussed challenges of the middle level that they did not want to face. Rebecca, a Southern elementary major, said "Their bodies are changing and [teachers] have to deal with puberty. I really didn't want to have to do that.” Nicole, another Southern elementary major, said "I think middle school's too crazy, or just like there's a lot going on developmentally and academically in middle school." Kari, an Eastern secondary major, said, "One of my [orientation] trainers told me that she was going to recommend that I stayed with the uptown kids because the downtown kids were gonna chew me up and spit me out because they can be so difficult ... Some of them can be very hard-headed and difficult. Gotta love puberty."

Finally, Patricia, an Eastern special education major, had negative perceptions of middle school but saw it as an opportunity to learn. She said that she was interested in why young adolescents feel disconnected, even though people claim that middle school is "scary." She said, “it's puberty time and-but I'm interested in that scary. I want to know why it's so scary."

\section{Implications for Recruitment Practices}

These TCs focused on their needs and on negative perceptions of middle school rather than on who young adolescents are or on what they need to become agentic learners. In terms of recruitment, this focus on how teaching middle school affects the teacher should be addressed early_well before the TC enters field experiences. If TCs are introduced to middle level classrooms before they can sharpen deficit views, they may be more interested in teaching at that level. We suggest the following practice to counteract this focus on adult needs and interests: 
Think About Middle Level Students. Cook-Sather and Youens (2007) advocated repositioning students within teacher education. Specifically, they reported on two programs that positioned PK-12 students as mentors to TCs, accomplished through correspondence and face-toface meetings. Incorporating opportunities like these into middle level teacher recruitment would facilitate reciprocal learning for TCs and may encourage student-centered thinking. If done in programs like ours, we could potentially encourage TCs to pursue teaching at the middle level.

\section{Resistance to Student Agency}

Across programs and universities, TCs often lamented students' attempts to enact agency. This was typically related to intentionality and self-regulation (Bandura, 2006). For many TCs, agency manifested as "attitude.” Ashley, a Southern elementary major, said, "they were already starting to get the attitude ... Kind of just like sass in a way but also this attitude of 'I don't care." Amber, an Eastern physical education major, explained that young adolescents are "more independent" than elementary learners, so teachers do not have to "do as much for them." However, she said, "you just gotta deal with more attitudes."

Olivia, a Southern middle grades major, explained that middle school teachers who provided "a lot of love and attention and confidence" had more control which she viewed as important at the middle level. Jay, an Eastern physical education TC, said, "You're going to have those kids who think they are older, who don't want to listen." Barbara, a Southern elementary major, said that in middle school,

They're figuring out who they are and so they want to challenge more and they're more likely to not be able to explain themselves like younger children . . . I think that there's a period of like three years that they can't tell you, because they don't even know. 
Each of these TCs demonstrated a deficit view of young adolescents in terms of their enacting their own voice and control, and Barbara in particular did not seem to believe that middle level students can engage in self-regulation or self-reflection.

\section{Implications for Recruitment Practices}

Think outside the academic year. Towson University began the Teacher Scholars Summer Institute to recruit high school students into teaching (Martinez-Alba, 2019). Students serve as camp counselors and earn dual enrollment credit to begin their college careers. This program has the added benefit of a focus on recruiting people of color. Middle level summer programs are an excellent opportunity to expand this initiative. Participants would need to be prepared to apply an asset lens in the experience_- perhaps through readings, discussions, and/or writing. AMLE’s This We Believe (Bishop \& Harrison, 2021) provides an asset-focused framework for this work. Our TCs' responses suggested to us that an asset lens and its link to recruitment should be leveraged well before teacher preparation in colleges and universities begins.

Think about partnerships. The "home grown" approach often evident in teacher recruitment is based on the rationale that many teachers want to work in their communities. Dual enrollment high school classes can focus on middle level learners and their funds of knowledge (Moll et al., 1992), which could motivate students to matriculate to that university. However, it is important to ensure that the programs are truly equitable, reduce barriers to licensure, and sustain TCs in the profession, especially those from historically marginalized groups (Gist et al., 2018).

\section{Challenging the Deficit Narrative}

While the other two themes were present across elementary, middle level, secondary, and PK-12 programs, this theme was only present in TCs who did not initially choose to teach 
middle school but changed their perspective after working with middle level learners. We see this as a type of conversion that suggests TCs in various programs are a potential pool for recruiting candidates for middle level teaching. We do not wish to imply a causal relationship between the education programs and the change in mindset, but we hope to explore a few ideas about why they may have developed an asset orientation toward young adolescents.

Only two TCs challenged the deficit narrative, and we chose to include their data here to demonstrate that developing an asset orientation may be partly due to exposure to young adolescents: understanding young adolescent development; experiencing the structure of a middle school; developing curriculum; planning, teaching, and assessing at the middle level; advocating for middle level education; and working toward social justice in middle schools (McEwin \& Smith, 2013). Jane — a female, secondary math major from Southern —and George — a male, secondary history major from Eastern—both entered their teacher preparation programs with a love for their content and a desire to explore complex topics with students. Both have maintained that goal, but over time, they learned to value the social-emotional learning of young adolescents and to challenge the pervasive deficit narrative around middle level learners.

Jane and George entered their middle level field placements having internalized the pervasive negative perceptions of middle schoolers. George said, "A lot of people have that perception ... [that] middle schoolers are going to want to scream and kick and still stand up every five seconds and be very disruptive." Jane echoed this sentiment, "I always heard middle schoolers were terrible and they were terrible to deal with.” However, their time working with young adolescents in their field placements challenged this mindset. George continued, You have these stereotypes of how they're gonna act as students, that they need to be babysat or they need to keep being yelled at. The weird, awkward stuff you have to face 
in the hallway. And then you see that in public where they are finally being themselves, being more comfortable, trying all the new things, being obnoxious and so forth. But as students, what I notice, is that they still are good students. They still sit down and want to learn and want to participate in a classroom. I think that's what people need to see.

George explained that what people see young adolescents doing in public is performative and a function of their growth, but in the classroom, they want to learn. When they feel less visible, they are able to be more authentic. In Jane's perspective, "the perceptions we have of middle schoolers are not necessarily accurate." She explained that teachers who are not "loving, caring and supportive of" middle level learners cause them to act out, which in turn causes misconceptions about young adolescents. In other words, she recognized the adult's role in creating behaviors that are seen as undesirable in schools.

While George and Jane are still interested in teaching high school, they appreciate middle schoolers for who they are and do not see them as much different from high schoolers. The only thing keeping them from becoming middle school teachers is the content- they are interested in spending longer class periods digging into complex content that is not covered in the middle grades. George explained,

It really is important to try to get out there and actually try to teach kids of middle school with an open mind. I've learned that middle school is really harshly perceived. So, if you were to be able to come into an open mind, you could see that there's really nothing different from high school.

The first two findings demonstrated that, when discussing teaching at the middle level, most TCs focused on themselves and how teaching young adolescents would affect them rather than on who their students were as people. Jane and George discussed getting to know the 
students, and those interactions helped them see young adolescents as valuable, misunderstood, and agentic. Their field experiences with young adolescents indicate that programs should provide TCs the opportunity to develop a love and appreciation for young adolescents before they decide on a grade level to teach, as this might assist with middle level recruitment efforts.

\section{Implications for Recruitment Practices}

Think small. Many sites implementing Robert Noyce Teacher Scholarship programs (National Science Foundation, n.d.) utilize micro experiences in the field to recruit teachers. Undergraduate students majoring in science, technology, engineering, and math fields are monetarily incentivized to complete field experiences and a reflection activity. Thus, undergraduates learn about teaching firsthand and whether it is the right career for them. Much like other suggestions for recruitment that we noted, participants would need to be prepared to apply an asset focus through activities involving reading, discussion, and reflection.

\section{Conclusion}

As many teacher preparation programs turn their attention to recruiting TCs in the coming years in the current climate of teacher shortages, it will be critical for programs to ensure they are recruiting candidates who are student centered, embrace student agency, and challenge deficit notions about middle level learners. If we recruit TCs who enter classrooms without a strong asset orientation to the children whom they serve, it could affect student achievement and overall wellbeing. Now is the time for educators to lead the way through innovating recruitment, preparation, and retention. We view it as our responsibility to reframe the deficit narrative around middle level learners to prevent their marginalization, and we are excited to take on this challenge in our own programs. 


\section{References}

Author 4, Author 2, \& Author 3. (in press). "A brave group of people":

Teacher candidates' perceptions of teaching in middle school.

Balfanz, R. (2009). Putting middle grades students on the graduation path: A policy

and practice brief. National Middle School Association.

https://www.amle.org/portals/0/pdf/articles/policy_brief_balfanz.pdf

Bandura, A. (2006). Toward a psychology of human agency. Perspectives on Psychological Science, 1(2), 164-180. https://www.jstor.org/stable/40212163

Bishop, P. A. \& Harrison, L. M. (2021). The successful middle school: This we believe. Association for Middle Level Education

Bishop, P. A., \& Nagle, J. F. (2016). The case for specialized middle grades teacher preparation, 2(1), 1-3. https://scholarworks.uvm.edu/mgreview/vol2/iss 1/1

Casas, F. (1997). Children's rights and children's quality of life: Conceptual and practical issues. Social Indicators Research, 42(3), 283-298.

Clark, A. (2010). Transforming children's spaces: Children's and adults' participation in designing learning environments. Routledge.

Cook-Sather, A., Youens, B. (2007). Repositioning students in initial teacher preparation: A comparative descriptive analysis of learning to teach for social justice in the United States and England. Journal of Teacher Education, 58(1), 62-75.

doi:10.1177/0022487106296216

Demink-Carthew, J., \& Bishop, P. A. (2017). Passion is not enough: Preparing middle level preservice teachers to be advocates for change. Middle School Journal, 48(2), 14-23.

DiAngelo, R. (2018). White fragility: Why it's so hard for White people to talk about racism. 


\section{Beacon Press.}

Faulkner, S., Cook, C., Thompson, N., Howell, P., Rintamaa, M., \& Miller, N. (2017). Mapping the varied terrain of specialized middle level teacher preparation and licensure. Middle School Journal. 48(2), 7-13. doi: 10.1080/00940771.2017.1272911

Fuller, F. F. (1969). Concerns of teachers: A developmental conceptualization. American Educational Research Journal, 6(2), 207-226.

Granger, N. (2013). Marginalization: The pendulum swings both ways. The New Existentialists. https://www.saybrook.edu/blog/2013/04/05/04-05-13/

Gist, C. D., Bianco, M., \& Lynn, M. (2018). Examining grow your own programs across the teacher development continuum: Mining research on teachers of color and nontraditional educator pipelines. Journal of Teacher Education, 70(1), 13-25. https://doi.org/10.1177/0022487118787504

Harper, S. R. (2012). How higher education researchers minimize racist institutional norms. The Review of Higher Education, 36(1), 9-29. https://web-app.usc.edu/web/rossier/publications/231/Harper\%20(2012)\%20RHE.pdf

Howell, P., Cook, C., Miller, N., Thompson, N., Faulkner, S., \& Rintamaa, M., (2018). The complexities of middle level teacher certification: Status report and future directions. Research in Middle Level Education Online, 41(4), 1-12. doi:10.1080/19404476.2018.1456840

James, A., \& Prout, A. (1997). Preface to second edition. In A. James \& A. Prout (Eds.), Constructing and reconstructing childhood: Contemporary issues in the sociological study of childhood (pp. ix -xvii). Falmer Press.

Kirby, P., Lanyon, C., Cronin, K., \& Sinclair, R. (2003). Building a culture of participation: 
Involving children and young people in policy, service planning, delivery and evaluation. Department for Education and Skills. National Children's Bureau.

\section{http://www.gyerekesely.hu/childpoverty/docs/involving_children_report.pdf}

Lesko, N., \& Mitschele, K. (2013). Rethinking Adolescence. In P. G. Andrews (Ed.), Research to guide practice in middle grades education (pp. 105-127). Association for Middle Level Education.

Lounsbury, J. H. (2013). Middle level education: A chronological history and a personal perspective. In P. G. Andrews (Ed.), Research to guide practice in middle grades education (pp. 11-49). Association for Middle Level Education.

Martinez-Alba, G. (2019, October 15). Exploring careers in education at Teacher Scholars Summer Institute. https://edprepmatters.net/2019/10/exploring-careers-in-education-at-teacher-scholars$\underline{\text { summer-institute/ }}$

Mayall, B. (1998). Towards a sociology of child health. Sociology of Health \& Illness, 20(3), 269-288.

Mayall, B., Bendelow, G., Storey, P., \& Veltman, M. (1996). Children's health in primary schools. Falmer Press.

McEwin, C. K., \& Smith, T. W. (2013). The professional preparation of middle grades teachers. In P. G. Andrews (Ed.), Research to guide practice in middle grades education (pp. 679695). Association for Middle Level Education.

Moll, L. C., Amanti, C., Neff, D., \& Gonzalez, N. (1992). Funds of knowledge for teaching: Using a qualitative approach to connect homes and classrooms. Theory Into Practice, 31(2), 132-141. https://doi.org/10.1080/00405849209543534 
National Center for Teacher Residencies. (2021). Home page. https://nctresidencies.org/

National Science Foundation. (n.d.). Robert Noyce Teacher Scholarship Program. https://www.nsf.gov/funding/pgm_summ.jsp?pims_id=5733

Paris, D., \& Alim, H. S. (2014). What are we seeking to sustain through culturally sustaining pedagogy? A loving critique forward. Harvard Educational Review, 84(1), 85-100.

Salas, S., Jones, J. P., Perez, T., Fitchett, P. G., \& Kissau, S. (2013). Habla con ellos - Talk to them: Latinas/os, achievement, and the middle grades. Middle School Journal, 45(1), 1823.

Saldaña, J. (2009). The coding manual for qualitative researchers. SAGE Publications, Ltd.

South Carolina Department of Education. (2020). https://ed.sc.gov/data/reports/scde-educator-profession-reports/scde-educator-professionreports/critical-needs-areas/

Sutcher, L., Darling-Hammond, L., \& Carver-Thomas, D., (2016). A coming crisis in teaching? Teacher supply, demand, and shortages in the U.S. Learning Policy Institute. https://learningpolicyinstitute.org/product/coming-crisis-teaching

Vagle, M. D. (2013). Contextualizing middle grades teachers. In P. G. Andrews (Ed.), Research to guide practice in middle grades education (pp. 751-776). Association for Middle Level Education.

Valencia, R. R. (1997). The evolution of deficit thinking: Educational thought and practice. RoutledgeFalmer. 
Van Overschelde, J. P., Saunders, J. M., \& Ash, G. E. (2017). "Teaching is a lot more than just showing up to class and grading assignments": Preparing middle-level teachers for longevity in the profession. Middle School Journal, 48(5), 28-38.

Vaughn, M. (2018). Making sense of student agency in the early grades. Phi Delta Kappan, 99(7), 62-66.

Virginia Department of Education. (2020).

http://www.doe.virginia.gov/teaching/workforce_data/index.shtml

Wall, A., Massey, D., \& Vaughn, M. (2018). Research summary: Student agency. http://www.amle.org/BrowsebyTopic/WhatsNew/WNDet/TabId/270/artmid/888/articleid 1995/Student-Agency.aspx

Woodhead, M. (1997). Psychology and the cultural construction of children's needs. In A. James \& A. Prout (Eds.) Constructing and reconstructing childhood: Contemporary issues in the sociological study of childhood ( $2^{\text {nd }}$ ed.). Falmer. 


\section{Appendix}

\section{Methods}

Study design: This study employed is an emergent, qualitative design. This paper is based off of a larger project that included a questionnaire and interviews. Within this project, our goal was to identify TCs' perceptions of teaching at the middle level.

Study context: The questionnaire was administered twice between April and June 2018. Semistructured interviews were conducted at the first institution along with a small, liberal arts college in the southern United States between May 2018 and May 2019. This college had elementary, middle grades, and secondary programs and included participants from all programs. Research Questions:

- How do TCs in an asset-oriented teacher preparation program describe their perceptions of middle level education and young adolescents?

- What suggestions do TCs have to increase recruitment and retention of middle grades teachers?

Researcher positionality: Three of the researchers were professors in the education programs at the studied institutions and one researcher was a doctoral student at one of the institutions. The research was not connected with any specific course, but some of the researchers' students did elect to participate in the questionnaire and/or the interviews. All of the researchers approach their classes as advocates for PK-12 students.

Data collection techniques: The questionnaire included five open-ended questions about TCs' perceptions and experiences teaching middle school, one demographic question, and a final question soliciting participation in the interviews. The interviews utilized semi-structured protocols with open-ended questions that allowed for follow-up questions when necessary. 


\section{Table 1}

Participant Demographics

\begin{tabular}{cll}
\hline \multirow{2}{*}{ Demographic } & Eastern University $^{2}$ : 9 participants & Southern College: 17 participants \\
\hline \multirow{2}{*}{ Gender } & Female: 7 & Female: 16 \\
& Male: 2 & Male: 1 \\
\hline \multirow{2}{*}{ Ethnicity } & Black: 4 & Black: 1 \\
& Latina: 1 & Latina: 1 \\
& White: 4 & White: 15 \\
\hline \multirow{2}{*}{ Age } & 18-21: 3 & $18-21: 14$ \\
& $22-29: 2$ & $22-29: 0$ \\
& 30s: 2 & 30 s: 2 \\
& 40s: 2 & 40s: 1 \\
\hline \multirow{2}{*}{ Year } & First year/Sophomore: 1 & First year/Sophomore: 7 \\
& Junior: 4 & Junior: 6 \\
& Senior: 4 & Senior: 4 \\
\hline \multirow{2}{*}{ Program } & Elementary: 1 & Elementary: 10 \\
& Middle/Secondary: 5 & Middle: 4 \\
& Other: 1 SPED; 2 PE & Secondary: 3 \\
\hline
\end{tabular}

\footnotetext{
${ }^{2}$ All names of people and places are pseudonyms.
} 